\title{
Identifying interventions with Gypsies, Roma and Travellers to promote immunisation uptake: methodological approach and findings
}

Lisa Dyson ${ }^{1}$, Helen Bedford ${ }^{2}$, Louise Condon ${ }^{3}$, Carol Emslie ${ }^{4}$, Lana Ireland ${ }^{4}$, Julie Mytton ${ }^{5}$, Karen Overend ${ }^{1}$, Sarah Redsell ${ }^{6}$ Zoe Richardson ${ }^{1}$ and Cath Jackson ${ }^{1 *}$

\begin{abstract}
Background: In the UK, Gypsy, Roma and Traveller (GRT) communities are generally considered to be at risk of low or variable immunisation uptake. Many strategies to increase uptake for the general population are relevant for GRT communities, however additional approaches may also be required, and importantly one cannot assume that "one size fits all". Robust methods are needed to identify content and methods of delivery that are likely to be acceptable, feasible, effective and cost effective. In this paper, we describe the approach taken to identify potential interventions to increase uptake of immunisations in six GRT communities in four UK cities; and present the list of prioritised interventions that emerged.
\end{abstract}

Methods: This work was conducted in three stages: (1) a modified intervention mapping process to identify ideas for potential interventions; (2) a two-step prioritisation activity at workshops with 51 GRTs and 25 Service Providers to agree a prioritised list of potentially feasible and acceptable interventions for each community; (3) crosscommunity synthesis to produce a final list of interventions. The theoretical framework underpinning the study was the Social Ecological Model.

Results: Five priority interventions were agreed across communities and Service Providers to improve the uptake of immunisation amongst GRTs who are housed or settled on an authorised site. These interventions are all at the Institutional (e.g. cultural competence training) and Policy (e.g. protected funding) levels of the Social Ecological Model.

Conclusions: The "upstream" nature of the five interventions reinforces the key role of GP practices, frontline workers and wider NHS systems on improving immunisation uptake. All five interventions have potentially broader applicability than GRTs. We believe that their impact would be enhanced if delivered as a combined package. The robust intervention development and co-production methods described could usefully be applied to other communities where poor uptake of immunisation is a concern.

(Continued on next page)

\footnotetext{
* Correspondence: cath@validresearch.co.uk

'Department of Health Sciences, University of York, Heslington, York YO10

5DD, UK

Full list of author information is available at the end of the article
}

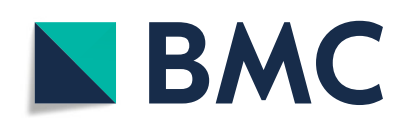

(- The Author(s). 2020 Open Access This article is licensed under a Creative Commons Attribution 4.0 International License, which permits use, sharing, adaptation, distribution and reproduction in any medium or format, as long as you give appropriate credit to the original author(s) and the source, provide a link to the Creative Commons licence, and indicate if changes were made. The images or other third party material in this article are included in the article's Creative Commons licence, unless indicated otherwise in a credit line to the material. If material is not included in the article's Creative Commons licence and your intended use is not permitted by statutory regulation or exceeds the permitted use, you will need to obtain permission directly from the copyright holder. To view a copy of this licence, visit http://creativecommons.org/licenses/by/4.0/. The Creative Commons Public Domain Dedication waiver (http://creativecommons.org/publicdomain/zero/1.0/) applies to the data made available in this article, unless otherwise stated in a credit line to the data. 
(Continued from previous page)

Study registration: Current Controlled Trials ISRCTN20019630, Date of registration 01-08-2013, Prospectively registered.

Keywords: Co-production, Gypsy, Immunisation, intervention development, Roma, Traveller

\section{Background}

In the UK, Gypsy, Roma and Traveller (GRT) communities are generally considered to be at risk of low or variable immunisation uptake. This is based on data demonstrating low uptake of preventive health services [1-4], the findings of a small number of local studies assessing immunisation take up using self-report or $\mathrm{Na}$ tional Health Service (NHS) records (e.g. [5, 6]), and publicised outbreaks of measles and whooping cough $[6$, 7]. Disease outbreaks amongst clusters of people pose a threat to wider community health even in countries where national and regional coverage is high [8].

The barriers to uptake by GRT communities reflect two groups of influencing factors for immunisation uptake in the general population and high-risk groups [9-11], namely access to services and beliefs about the necessity of vaccines or concerns about their safety. Although some differences exist between communities, our research [1214] and other studies with diverse GRT communities [1$4,15,16]$ report that these groups encounter challenges accessing health services, including immunisation. These are often related to socio-economic and socio-cultural barriers for example, poverty, low literacy, discrimination leading to a lack of trust in health professionals, irregular school attendance, poor/changing housing conditions and language. The absence of a permanent postal address to register with a General Practitioner (GP) and difficulty securing prompt immunisation appointments are additional, practical, access barriers [12-14]. Studies exploring GRT views on immunisation report mixed acceptance [12-18], resistance to immunisations is associated with concerns about the potential side effects and/or a lack of belief in their value.

These multiple, complex and often interlinked factors mean that a broad range of approaches at individual, provider, health system, and national levels are needed to ensure optimum immunisation uptake. Many strategies that are developed and evaluated for the general population [19-22] are relevant for GRT communities, however additional or different approaches may be required. Importantly, one cannot assume that "one size fits all" because the cultural beliefs and established traditions of different GRT communities can vary $[1-4,12-$ 14]. Robust intervention development is required to identify content and methods of delivery that are likely to be acceptable, feasible, effective and cost effective. Different approaches to intervention development exist and include guidance from the United Kingdom (UK) Medical Research Council (MRC) [23, 24], intervention mapping [25], behaviour change techniques [26] and guidelines specifically for tailoring immunisation programmes [27, 28]. In the UK and North America, there has been growing interest in applying co-production methods to public services such as health and social care [29]. Indeed, working with the target community to ensure that interventions and services are grounded in its views and experiences (process of co-production) is a hallmark of good quality care [30, 31]. Existing interventions with GRT communities focus on immunisation (e.g. pop-up immunisation clinics) or target preventive health more broadly (e.g. hand-held patient records) [1, 32-34]. However, they are rarely developed through exploring the multiple facets to GRT's current behaviour in order to identify areas for potential intervention.

Our UNITING (UNderstanding uptake of Immunisations in TravellIng aNd Gypsy communities) study drew on the aforementioned guidance to systematically use evidence, theory, population segmentation and methods of co-production. It had two aims: (1) Investigate the barriers and facilitators to acceptability and uptake of immunisations amongst six GRT communities across four UK cities; (2) Identify potential interventions to increase uptake of immunisations in these GRT communities. The six communities were: Eastern European Roma and English Gypsy/Irish Traveller (Bristol), English Gypsy (York), Eastern European Roma and Scottish Showpeople (Glasgow), and Irish Traveller (London). The theoretical framework underpinning the study was the Social Ecological Model (SEM) [35] which recognises that the determinants of individuals' behaviour are complex, multifaceted and operate at different levels (intrapersonal, interpersonal, institutional, community, policy). UNITING was a three-phase study. The methods and findings for the first two phases, interviews with GRTs and Service Providers, are presented elsewhere $[12-14,36,37]$. In this paper, we discuss the third phase of UNITING, the approach we took to identify potential interventions to increase uptake of immunisations in these GRT communities; and present the list of prioritised interventions that emerged.

\section{Methods}

This work was conducted in three stages (see Fig. 1). Each stage informed the next. 
Interviews with GRT communities and their Service Providers

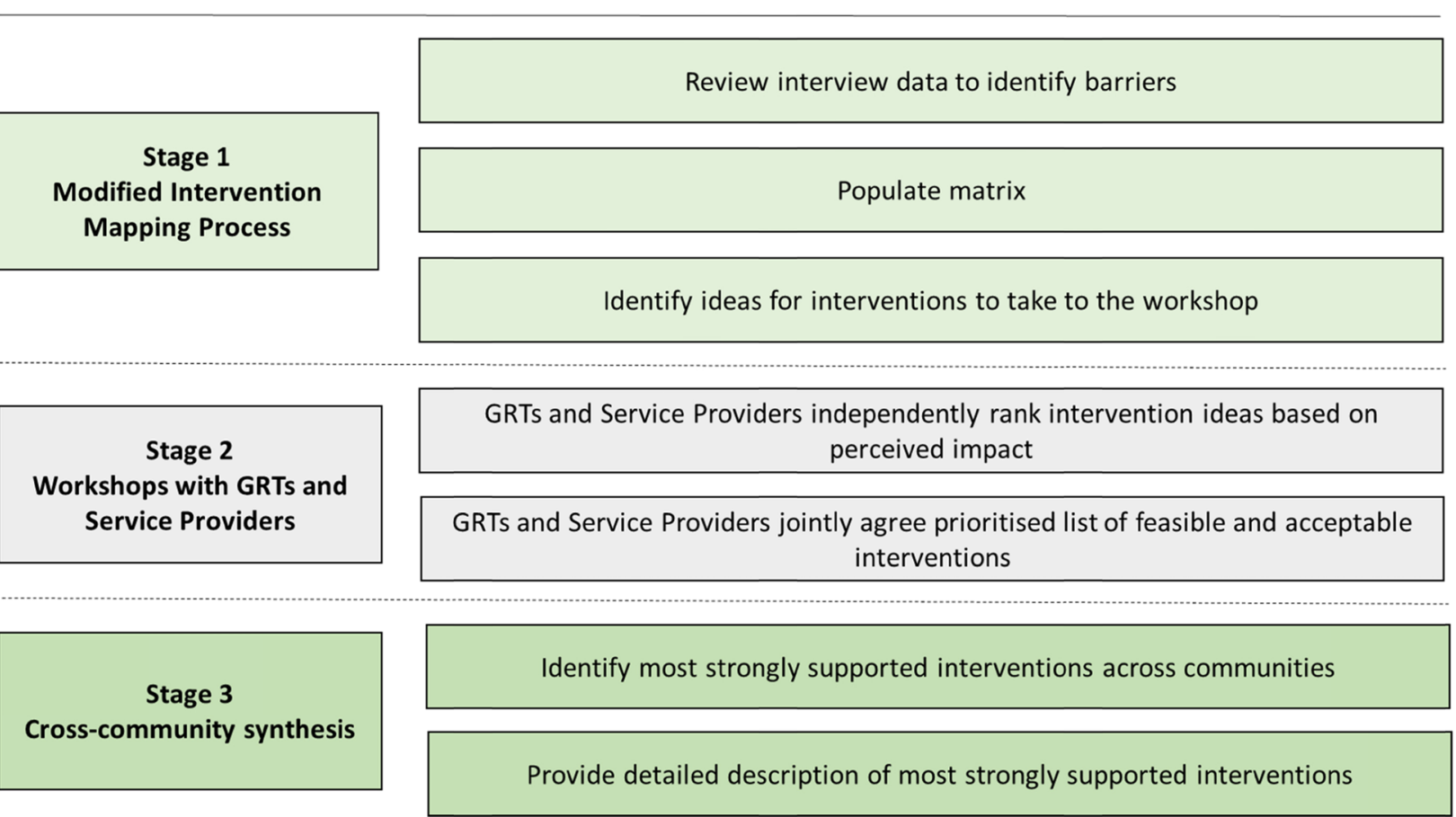

Fig. 1 Stages of intervention development and assessment

1. A modified intervention mapping process [25] using interviews previously conducted with GRTs and Service Providers [12-14] to identify ideas for potential interventions

2. Workshops with GRTs and Service Providers to agree a prioritised list of potentially feasible and acceptable interventions for each community

3. Cross-community synthesis to produce a final list of prioritised interventions

\section{Stage 1 - Modified intervention mapping process}

A modified intervention mapping approach [25] was used to identify key ideas for interventions to be taken to workshops in Stage 2. This method uses theory and evidence to map "the path from recognition of a need or problem to the identification of a solution" [25]. The data from our interviews with GRTs and Service Providers [12-14] were used as evidence to identify the "need or problem" that could potentially be changed through intervention. Our focus was GRTs who were housed or settled on an authorised site because these were our interview participants. We did not recruit any GRTs living on the roadside or on unauthorised encampments to be interviewed. We sought to identify acceptable ideas for interventions at all five levels of the SEM [35], creating matrices which linked the barriers to immunisation, objectives to address each barrier, intervention target, SEM level and intervention ideas (see Table 1 for an example).

To generate as many potential interventions as possible, ideas were drawn from interviews with GRTs in the target community and their Service Providers, from interviews with GRTs from the other communities and their Service Providers, and from the knowledge and experience of the research team and advisory group. Two researchers independently mapped intervention ideas to the barriers, objectives, targets and SEM level and then jointly agreed the intervention ideas to take to the workshops. These fell into three categories: promoting awareness and understanding of immunisation, developing trust and respect, and improving immunisation services. The matrices produced for the first two communities (Bristol Eastern European Roma and Bristol English Gypsy/Irish Travellers) were used as a framework from which to build the matrices for the other communities, incorporating additional or adapted interventions based on the interviews. See Table 2 for the intervention ideas that were taken to the York workshop.

\section{Stage 2 - Workshops with GRTs and Service Providers}

The aim of the workshops was to "co-produce" [29] a prioritised list of interventions to increase immunisation 
Table 1 Example from an intervention mapping matrix (Bristol English Gypsy//rish Traveller community)

\begin{tabular}{|c|c|c|}
\hline Barrier & $\begin{array}{l}\text { Concerns about specific vaccines: } \\
\text { Whooping cough - fear of brain damage in child, view that pregnancy should be natural } \\
\text { HPV - belief that girls don't need it as don't have sex until married, so vaccine is seen as } \\
\text { inappropriate and offensive }\end{array}$ & $\begin{array}{l}\text { Low levels of literacy: } \\
\text { meaning that information about immunisations is } \\
\text { difficult to understand }\end{array}$ \\
\hline $\begin{array}{l}\text { Objective to } \\
\text { address barrier }\end{array}$ & $\begin{array}{l}\text { Develop good understanding of specific vaccines amongst GRTs whilst mindful of } \\
\text { culturally-based concerns }\end{array}$ & $\begin{array}{l}\text { Develop good understanding of immunisations } \\
\text { amongst GRTs }\end{array}$ \\
\hline Target: & $\begin{array}{l}\text { Community } \\
\text { Primary Care } \\
\text { Schools }\end{array}$ & $\begin{array}{l}\text { Community } \\
\text { Primary Care }\end{array}$ \\
\hline SEM level & $\begin{array}{l}\text { Intrapersonal } \\
\text { Interpersonal } \\
\text { Institutional } \\
\text { Community }\end{array}$ & $\begin{array}{l}\text { Intrapersonal } \\
\text { Institutional }\end{array}$ \\
\hline $\begin{array}{l}\text { Ideas for } \\
\text { Intervention }\end{array}$ & $\begin{array}{l}\text { Verbal explanation from a health professional }{ }^{\mathrm{a}} \\
\text { Community Champions }^{\mathrm{a}} \\
\text { Social media with accurate messages }{ }^{\mathrm{a}} \\
\text { Work with school nurses to change the way the HPV jab is presented to adolescent girls } \\
\text { i.e. about cancer and when it is important to have it }{ }^{b} \\
\text { Cultural competence training; Work with targeted groups e.g. pregnant women, fathers, } \\
\text { adolescent girls }{ }^{c} \\
\text { Support adolescent girls to speak with their elders }{ }^{c} \\
\text { Involve the community in developing culturally relevant information }{ }^{c}\end{array}$ & $\begin{array}{l}\text { Explain things clearly and where information is written } \\
\text { keep it simple using pictures } \\
\text { Involve the community in developing accessible } \\
\text { information } \\
\text { Improve access/retention at school }^{c}\end{array}$ \\
\hline
\end{tabular}

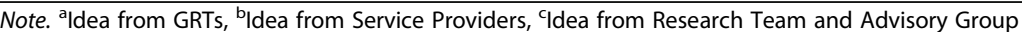

Table 2 Ideas for interventions taken to the York workshop with independent and jointly agreed rankings

\begin{tabular}{|c|c|c|c|}
\hline Ideas for Intervention & $\begin{array}{l}\text { English Gypsies' } \\
\text { rankings }\end{array}$ & $\begin{array}{l}\text { Service Providers' } \\
\text { rankings }^{\mathrm{a}}\end{array}$ & $\begin{array}{l}\text { Jointly agreed } \\
\text { rankings }\end{array}$ \\
\hline \multicolumn{4}{|l|}{ Promoting awareness and understanding of immunisation } \\
\hline Good information from non-NHS sources e.g. magazines, social media & 9 & $=1$ & \\
\hline Insert into Red Book that is clear and simple, designed by GRTs & 10 & & \\
\hline $\begin{array}{l}\text { Appropriately designed leaflets and verbal personalised information from trusted Health } \\
\text { Professional in GP practice }\end{array}$ & 7 & $=1$ & $=4$ \\
\hline $\begin{array}{l}\text { Appropriately designed leaflets and verbal personalised information from trusted Health } \\
\text { Professional at home }\end{array}$ & $=3$ & $=1$ & $=4$ \\
\hline $\begin{array}{l}\text { Training for Health Professionals to identify those most concerned about immunisations } \\
\text { to discuss their fears and concerns }\end{array}$ & $=4$ & & \\
\hline \multicolumn{4}{|l|}{ Developing trust and respect } \\
\hline $\begin{array}{l}\text { Cultural Competence Training for Health Professionals, Frontline Staff and other Service } \\
\text { Providers who work with GRTs }\end{array}$ & $=4$ & $=1$ & 3 \\
\hline $\begin{array}{l}\text { Named person in GP practice who is trusted by the community for frontline service at } \\
\text { reception desk and link to Health Professionals }\end{array}$ & $=3$ & $=1$ & \\
\hline \multicolumn{4}{|l|}{ Improving immunisation services } \\
\hline $\begin{array}{l}\text { Multi-sectorial working led by Health Professionals to raise understanding of cultural } \\
\text { issues among professionals in all sectors }\end{array}$ & 5 & $=1$ & \\
\hline Flexible and diverse approach to booking appointments, recall and reminder systems & 8 & $=1$ & \\
\hline $\begin{array}{l}\text { Flexible delivery of immunisation services to meet specific needs of most socially } \\
\text { excluded GRTs, e.g. drop-in clinics, outreach }\end{array}$ & & $=1$ & \\
\hline Protect funding of specialist roles, e.g. Health Visitor post dedicated to GRT communities & $=3$ & $=1$ & 1 \\
\hline $\begin{array}{l}\text { Improve joined up working and planning between diverse organisations involved in } \\
\text { commissioning and delivery of immunisation services }\end{array}$ & & & 5 \\
\hline Representation from GRT community at meetings of local Immunisation committees & 2 & & \\
\hline Identify GRTs in health records to record immunisation uptake and tailor support & 1 & $=1$ & 2 \\
\hline Improve system of temporary registration at GP practices & 6 & & \\
\hline
\end{tabular}

Note. Independent rankings were based on perceived impact. 1 = greatest impact. Jointly agreed rankings were based on perceived impact, acceptability and

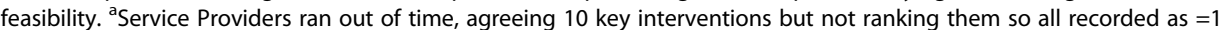


uptake; and to discuss the content and delivery of these interventions for each community. Five half-day workshops were held from November 2014 to September 2015: one workshop in Bristol attended by both the Roma and English Gypsy/Irish Traveller communities, one workshop in York and in London, and two workshops in Glasgow - one each for the Eastern European Roma community and the Scottish Showpeople. Fiftyone GRTs and 25 Service Providers attended a workshop (see Table 3). Prior to commencing each workshop written consent was collected from participants. The workshops with the Roma participants were conducted with the assistance of interpreters (Romanian, Slovak).

In each workshop, following the spoken presentation of the key findings from the interviews by the local researcher, a structured and facilitated two-step process [38] was used to prioritise the interventions. First, GRTs and Service Providers worked in separate groups. The local researcher presented the ideas identified in stage 1 . Each idea was written on an A4 sheet of coloured paper and read out to the group with supporting detail from the interviews about the idea. Given that these ideas had emerged from the interview data we were confident that they were acceptable. Participants then discussed and scored each idea in terms of perceived impact (if this idea was adopted how much of a difference would it make to your/the local GRT community in having injections? $1=$ no difference to $5=a$ lot of difference). This ranking did not consider the potential ease or difficulty of implementation and their potential influence on perceived impact). Participants were also asked to identify potential barriers and facilitators to the ideas working in their community. At the end of this session, GRTs and Service Providers had both drawn up a ranked list of intervention ideas based on these impact scores. GRTs and Service Providers then came together and a facilitated discussion, including further discussion on feasibility, was conducted to produce a jointly agreed, prioritised list of five feasible and acceptable interventions which could positively impact on immunisation uptake in their community. As an example, Table 2 presents the independent and joint rankings of the intervention ideas from the York workshop.

\section{Stage 3 - Cross-community synthesis}

Emerging findings from stages 1 and 2 clearly revealed shared rankings, concerns and potential solutions, across communities. For some interventions, high impact rankings were assigned by GRT participants across communities but not by the Service Providers. For others, the reverse occurred. Therefore, stage 3 involved looking across both the independent GRT and Service Provider (impact) rankings and final co-produced, prioritised lists of interventions from each workshop to identify the five most consistently well supported interventions. Interventions needed to be in the top six of the independent rankings by the GRTs and/or Service Providers to be included in the final list. Interventions that were strongly

Table 3 Characteristics of GRTs and Service Providers who attended a workshop

\begin{tabular}{|c|c|c|c|c|c|c|c|c|c|}
\hline & & $\begin{array}{l}\text { Bristol } \\
\text { Roma }\end{array}$ & $\begin{array}{l}\text { Bristol } \\
\text { English } \\
\text { Gypsy }\end{array}$ & $\begin{array}{l}\text { Bristol Irish } \\
\text { Traveller }\end{array}$ & $\begin{array}{l}\text { York } \\
\text { English } \\
\text { Gypsy }\end{array}$ & $\begin{array}{l}\text { Glasgow } \\
\text { Romanian } \\
\text { Roma }\end{array}$ & $\begin{array}{l}\text { Glasgow } \\
\text { Slovakian } \\
\text { Roma }\end{array}$ & $\begin{array}{l}\text { Glasgow Scottish } \\
\text { Showpeople }\end{array}$ & $\begin{array}{l}\text { London Irish } \\
\text { Traveller }\end{array}$ \\
\hline \multicolumn{10}{|l|}{ GRT All } \\
\hline Total & 51 & 10 & 2 & 0 & 4 & 7 & 2 & 4 & 11 \\
\hline Mother & 18 & 5 & 1 & 0 & 4 & 3 & 1 & 2 & 1 \\
\hline Grandmother & 13 & 2 & 0 & 0 & 1 & 0 & 0 & 1 & 5 \\
\hline $\begin{array}{l}\text { Woman no } \\
\text { children }\end{array}$ & 4 & 0 & 1 & 0 & 2 & 0 & 0 & 1 & 2 \\
\hline $\begin{array}{l}\text { Adolescent } \\
\text { girl }\end{array}$ & 6 & 0 & 0 & 0 & 0 & 0 & 0 & 0 & 3 \\
\hline Father & 7 & 2 & 0 & 0 & 1 & 4 & 1 & 0 & 0 \\
\hline Grandfather & 2 & 1 & 1 & 0 & 0 & 0 & 0 & 0 & 0 \\
\hline $\begin{array}{l}\text { Male no } \\
\text { children }\end{array}$ & 1 & 0 & 10 & 0 & 0 & 0 & 0 & 0 & 0 \\
\hline \multicolumn{10}{|c|}{ Service Provider All } \\
\hline Total & 25 & 6 & & & 10 & 4 & & 1 & 4 \\
\hline $\begin{array}{l}\text { Frontline } \\
\text { workers }\end{array}$ & 15 & 3 & & & 5 & 3 & & 1 & 3 \\
\hline $\begin{array}{l}\text { Strategic } \\
\text { roles }\end{array}$ & 10 & 3 & & & 5 & 1 & & 0 & 1 \\
\hline
\end{tabular}

Note. The target sample was 10-12 GRTs from each community across family roles and 3-4 associated Service Providers 
supported but only by particular, usually one or two, communities and their Service Providers were also recorded. These are reported elsewhere [13].

At this stage a detailed description elaborated the nature of each intervention in accordance with the 'modelling process and outcomes' step in the MRC guidance on developing and evaluating complex interventions [23]. This included documenting any differences in content and delivery of the intervention required for different GRT communities.

\section{Results}

Five interventions emerged as most consistently supported across GRT communities and/or their Service Providers to improve uptake of immunisation among GRT who are housed or settled on an authorised site (see Fig. 2). The intervention most strongly supported by both GRT communities and Service Providers was 'Cultural competence training for Health Professionals and Frontline Staff', illustrated by the smallest circle. The other interventions that were prioritised with less consensus are represented by the circles that increase with size. All five interventions equated to Institutional and Policy levels of influence in the SEM [35].
Detail (components, delivery, differences, barriers) for the five interventions are presented in Table 4. The differences include where an intervention was not considered necessary for a community, for example "named frontline person in GP practice" for the Glasgow Scottish Showpeople; as well how content might differ, for example ensuring that cultural concerns about the HPV and pregnancy vaccines are included in cultural competence training for those working with English Gypsies/ Irish Travellers in Bristol.

\section{Discussion}

In this paper, we describe the approach taken to identify potential interventions that could increase uptake of immunisation in GRT communities which are housed or settled on an authorised site. We present the five interventions that emerged as most consistently supported across GRT communities and/or their Service Providers. We reflect here on the identification process and consider its strengths, challenges, and limitations. We then discuss the interventions in the context of existing practice, policy and research.

The key strength of our approach was that we used established methods for robust intervention

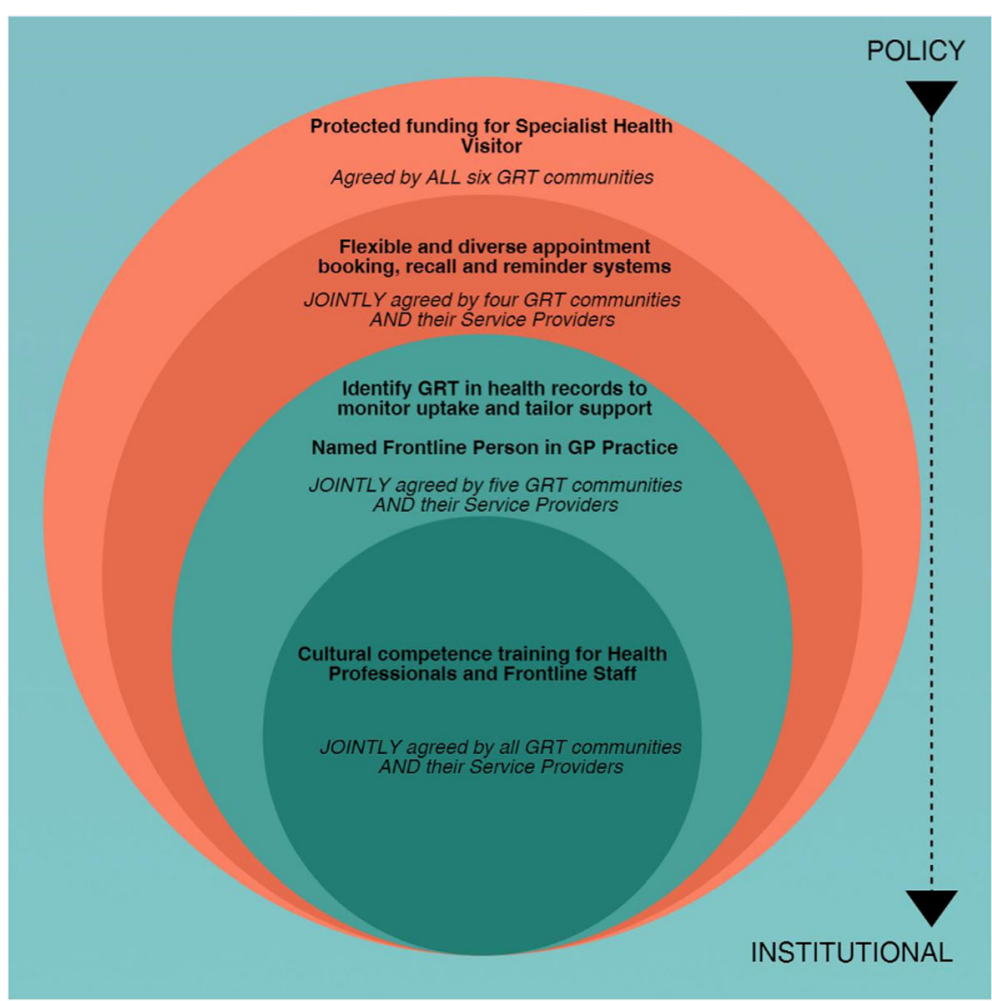

Fig. 2 Top priority interventions to improve uptake of immunisation, identified across GRT communities and Service Providers. Note: This image was previously published in Jackson, C. et al. (2016). Understanding uptake of Immunisations in Travelling aNd Gypsy communities (UNITING): a qualitative interview study. National Institute for Health Research, Health Technology Assessment, 20(72), 1-176. DOl: https://doi.org/10.3310/hta20720 


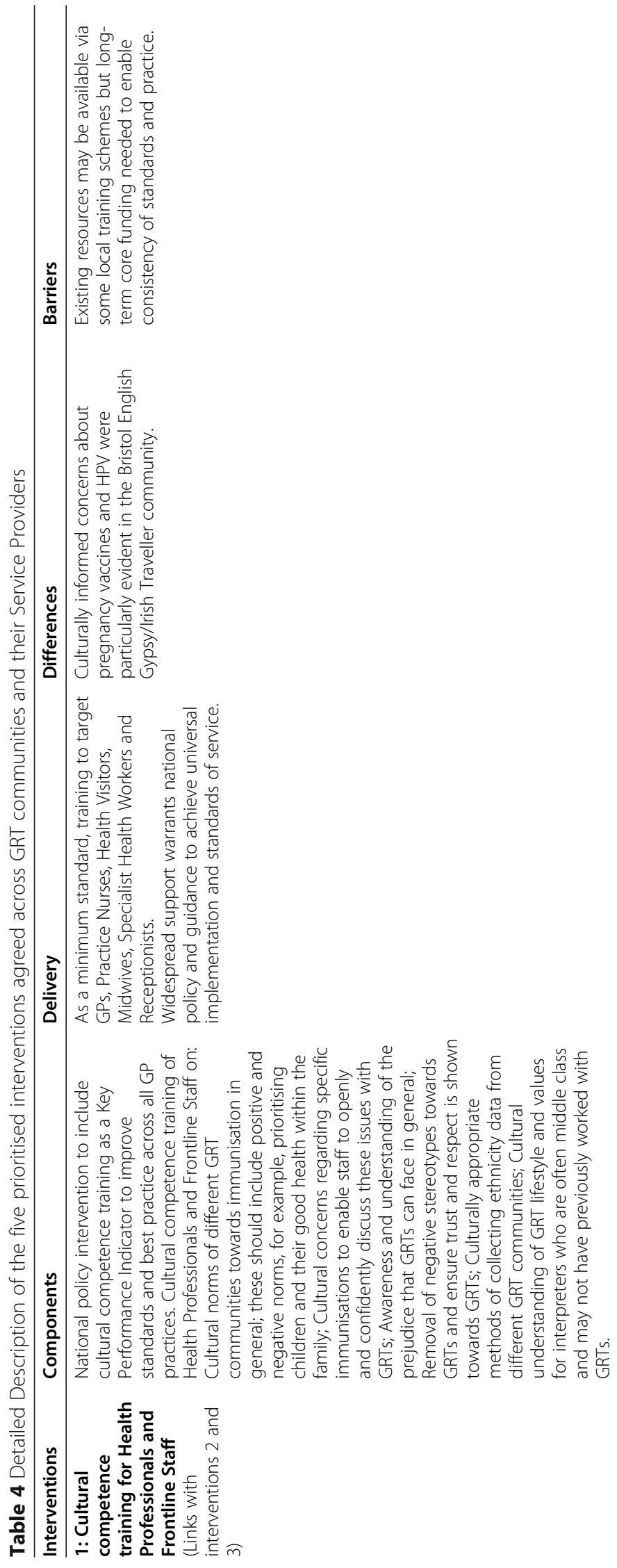

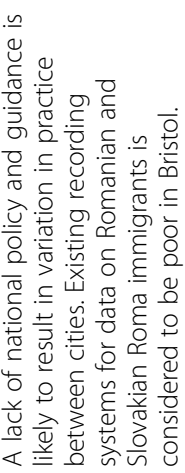
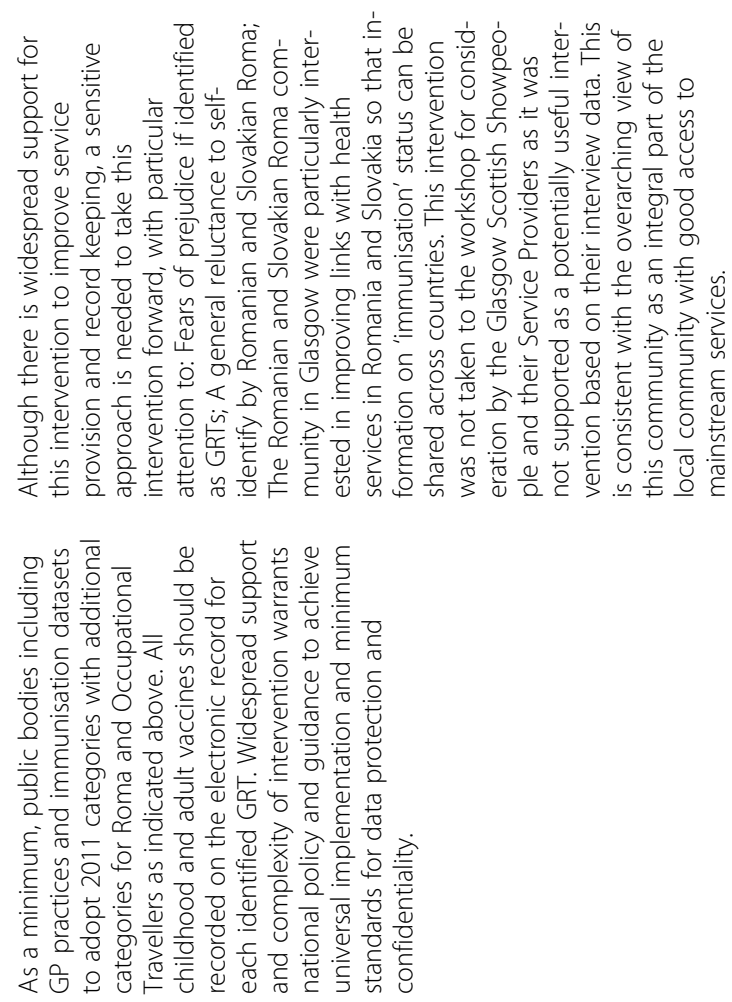

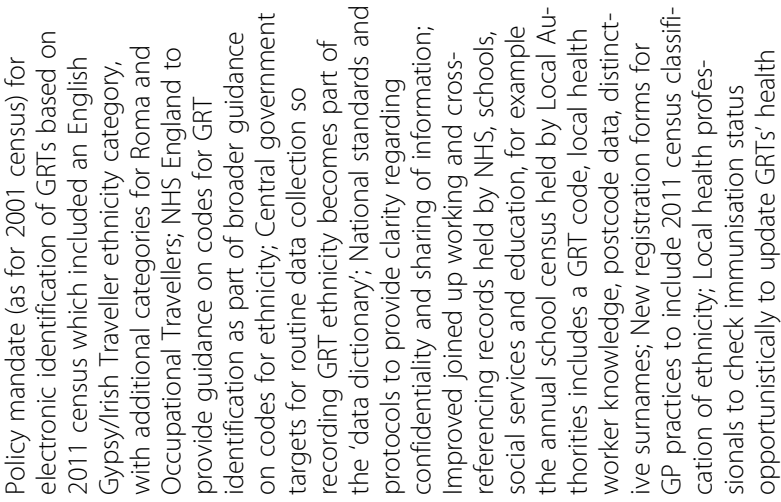

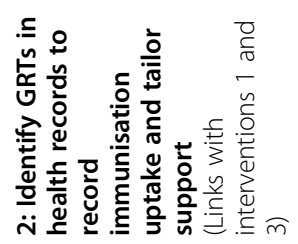



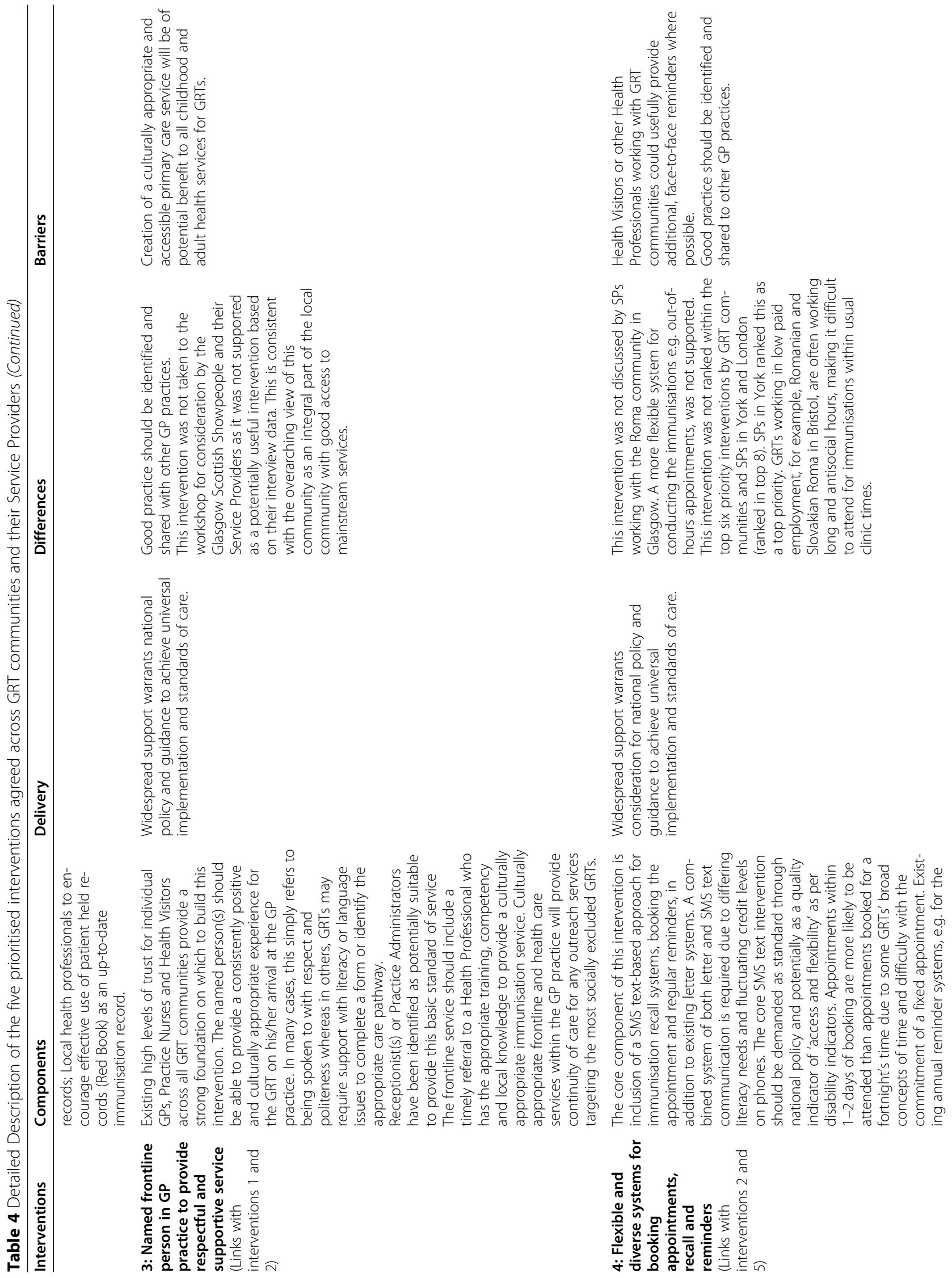


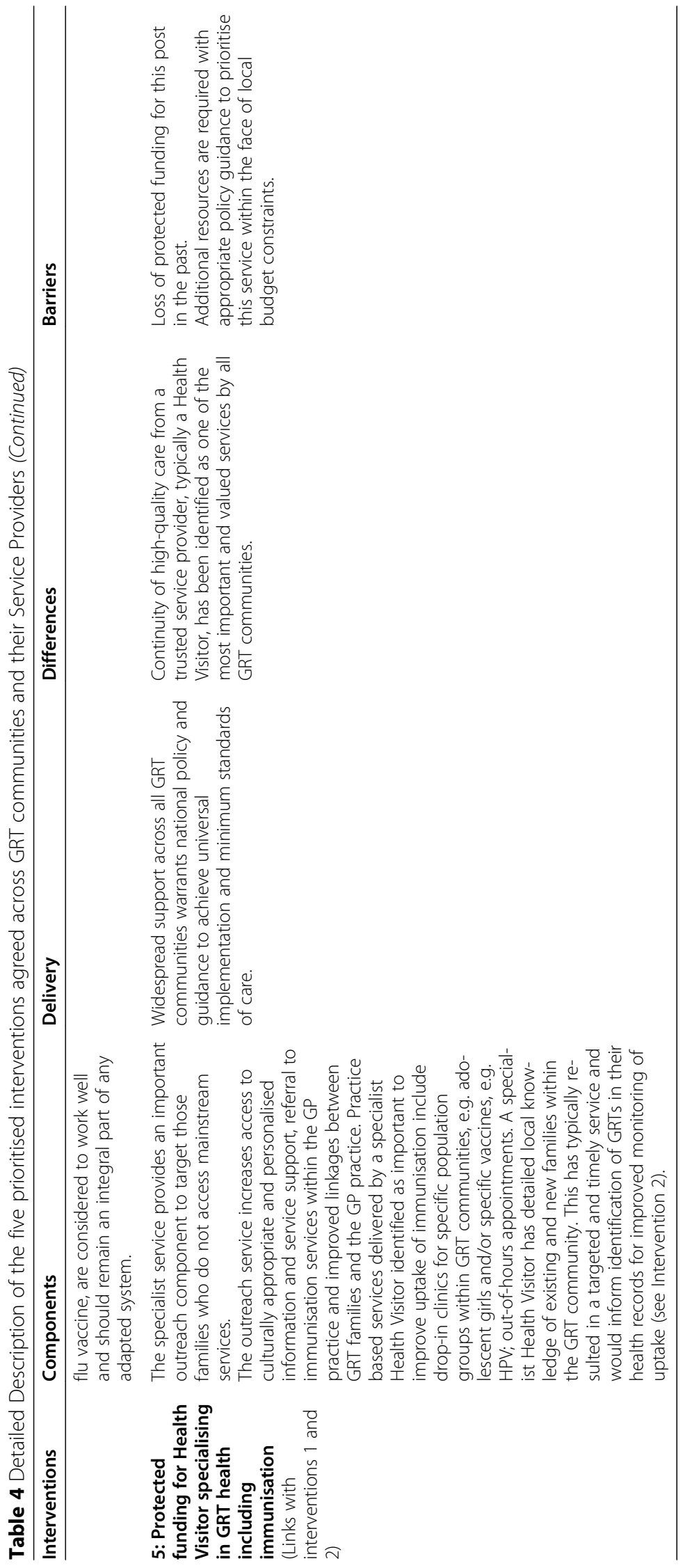


development $[23,25,29,38]$; we identified desired intervention outcomes (using intervention mapping), drew on evidence (interviews with the six GRT communities and their Service Providers), employed theory (SEM [35]), tailored the interventions to different segments of the population (different GRT communities) and worked in partnership with GRTs and their Service Providers to ensure that the final prioritised interventions were informed by their views and experiences. This grassroots experience also generated detailed insight into the barriers and facilitators to potential implementation of the five prioritised interventions which can inform their future development and evaluation [23]. Application of the SEM to "real-life" recommendations was useful in determining the level at which prospective interventions or changes in practice might best be targeted. The workshops were informal and highly interactive events with many GRTs and Service Providers commenting that this was the first time they had been given the opportunity to talk to each other about services. GRT participants were generally adept in highlighting applied and practical implications for practice. For example, in discussing the intervention "flexible and diverse appointment booking, recall and reminder systems" the Glasgow Scottish Showpeople offered the view that shared mailboxes in static caravan yards were a barrier to the timely receipt of immunisation appointments, and suggested that text messaging might be a preferable method. In some workshops, there was a lack of concordance in the independent impact rankings by GRTs and Service Providers (see "Good information from non-NHS sources" in Table 2) and therefore coming together and hearing a different perspective to generate the prioritised list of interventions with shared ownership was essential. A challenge of the workshops was completing the two steps of prioritisation in the time available. This meant that sometimes the first step discussions (when GRTs and Service Providers worked independently) were cut short and the interventions perceived to have greatest impact were agreed but not ranked (as occurred for the Service Providers in York, see Table 2). This was resolved in the second, joint-working, step, but it did mean that there were some missing data for the cross-synthesis. When this occurred, data from the remaining rankings were used.

It is important to consider how transferable the finalised list of interventions is to (1) other GRTs/Service Providers within these six communities and (2) other GRT communities in the UK. With respect to (1) we are confident the initial selection of intervention ideas (in stage 1) reflected wider community views as these were based on interviews with 174 GRTs across family roles and immunisation experiences; and 39 Service Providers in both frontline and strategic roles [12-14]. As such we are confident in the acceptability of the final interventions. We did not meet our target sample for the workshops for all six communities however, the transparent approach regarding the level of agreement within and across GRT communities and Service Providers for the five interventions (Fig. 2) is reassuring. In addressing (2) based on the above mentioned interviews [12-14], evidence suggests that these GRT communities share immunisation views, norms and experiences with communities of the same descent (e.g. other Irish Traveller communities) [12-17, 39-43]. We therefore believe that the five interventions are relevant to members of other GRT communities of English, Irish, Romanian/Slovakian Roma and Scottish Showpeople descent who are housed or settled on an authorised site. We do not know if these interventions would be prioritised by GRT communities who live on the roadside or in unauthorised encampments.

The final five prioritised interventions were all "upstream" interventions [44] and focused on addressing barriers of access to immunisation services rather than concerns about the safety or beliefs about the necessity of vaccines. Workshop participants were clear that these interventions were complementary and likely to have greater impact if delivered together. This is consistent with findings of a recent review [19] that locally developed, multicomponent interventions are most effective in reducing inequalities in immunisation uptake. Local implementation of the five interventions will need to reflect some differences in content and delivery between communities (see Table 4).

Interestingly, these proposed interventions were not necessarily new, nor were they unique to the needs of GRTs. The UK 2010 Equality Act [45] and other guidance for working with GRTs $[1,4,16,17,32,46]$ and other minority groups [47] acknowledge the importance of cultural competence training to develop Service Provider understanding of different cultures and the impact of discrimination with a view to building trustful relationships to enhance care. Strong monitoring and surveillance systems are an accepted component of a good immunisation programme $[19,48]$. Specific to GRTs, is the need to include an ethnicity category that enables them to self-identify. In England, the 2011 national census category "Gypsy or Irish Traveller" is not routinely used in NHS health systems, for example in GP practices and Child Health Information Systems [2, 49, 50]. Furthermore, this category does not enable Roma or Occupational Travellers to self-identify [2, 4], and when GRTs are not identified as distinct ethnic groups, understanding of their barriers to healthcare provision is limited $[2,4,51]$. Capturing this information would mean that patterns of health services utilisation, including immunisation, could be monitored to identify health inequalities [49] and tailor service provision to reduce 
inequalities $[2,4,49,52]$. The fear of discrimination may deter GRTs from self-identifying [4] again reinforcing the importance of delivering these interventions as a package. The combined effect is to create an environment in which GRTs feel safe to disclose their ethnicity.

The UK National Institute for Health and Care Excellence [53] and the World Health Organisation [48] recommend offering flexibility of booking and attending immunisation appointments to ensure that healthcare is accessible [3, 4, 30, 54]. Effective recall, reminder and appointment systems for childhood and adult vaccinations $[21,55]$ can be tailored to meet the specific needs of each GRT community. For example, rather than delivering specialist immunisation services to a community, it may be better to improve signposting and access to mainstream provision [33, 43, 54]. Finally, an important finding - which is rarely formally evaluated [33] - confirms that GRTs value the role that Specialist Health Visitors play in facilitating access to health services including immunisation [1,33,56]. Unfortunately, insight from our interviews with Service Providers $[12,14]$ suggested that these roles are no longer funded in all the study locations, meaning that access is inequitable.

\section{Conclusions}

The five prioritised interventions were Institutional and Policy level interventions, reinforcing the key role of GP practices, frontline workers and wider NHS systems on improving immunisation uptake. All five interventions have potentially broader applicability than GRT communities alone. The complementary nature of these interventions suggests that their impact would be enhanced if delivered as a combined package. Local implementation must reflect community differences. We have used robust intervention development and co-production methods which could usefully be applied to other communities where uptake of immunisation is a concern.

\section{Abbreviations \\ GP: General Practitioner; GRT: Gypsy, Roma and Traveller; MRC: Medical Research Council; NHS: National Health Service; SEM: Social Ecological Model; UK: United Kingdom; UNITING: UNderstanding uptake of Immunisations in Travelllng aNd Gypsy communities}

\section{Acknowledgements}

The UNITING research team would like to thank all the GRTs and Service Providers who took part in the workshops. We are also very grateful to our Community Partners and the Independent Project Advisory Group who guided us throughout the study; and to our collaborators who facilitated our contact with the GRT communities. These individuals are listed below. Without this support, our study would not have been possible. Thanks also to Paula Cowan (University of York) for providing administrative support and to Colin Clark and Lynn Poole (University of the West of Scotland) for their advice at the start of the study.

Community Partners

- Shirell Johnson, member of Glasgow Scottish Showpeople community

- Danielle Thomas, member of Glasgow Scottish Showpeople community

- London Gypsy and Traveller Forum

- York Travellers Trust Advisory Steering Group
Independent Project Advisory Group

- Martin Schweiger (Chair), Public Health Consultant, Public Health England

- Jill Edwards, Research Fellow, University of Leeds

- Patrice van-Cleemput, Freelance Research Consultant

Collaborators

- Hilary Beach, University of the West of England, Bristol

- Sarah Bridgman, North Somerset Community Partnership Community

Interest Company

- Francine M Cheater, University of East Anglia

- Annie Crocker, Member of English Gypsy Community, Bristol

- Gill Francis, North East London NHS Foundation Trust

- Bridget Gallagher, NHS Greater Glasgow \& Clyde

- Jacob Jablonowski, formerly Wellspring Healthy Living Centre, Bristol

- Philippa Kemsley, UCL Great Ormond Street Institute of Child Health,

London

- Susan Kerr, Glasgow Caledonian University

- Sheila Lally, North Bristol NHS Trust

- Helen J Lewis, University of York

- Anne Marie McCulloch, NHS Greater Glasgow \& Clyde

- Luiza McRae, Freelance Interpreter

- Christine Shepherd, York Travellers Trust

- Lesley Smith, York Travellers Trust

- Gillian Thomson, NHS Greater Glasgow \& Clyde

- Linda Vousden, North Bristol NHS Trust

- Lewisham Irish Community Centre

- Local Planning Group in Glasgow

- London Gypsy and Traveller Unit

- Southwark Traveller Action Group

- York Travellers Trust

\section{Authors' contributions}

LD contributed to study design, co-led stage 1 (intervention mapping) and led stage 3 (cross-community synthesis). HB contributed to study conception and design, stage 1 and co-led stage 2 (workshop) in London. LC contributed to study conception and design, stage 1 and co-led stage 2 in Bristol. CE contributed to study conception and design, stage 1 and co-led stage 2 in Glasgow. LI contributed to stage 1 and co-led stage 2 in Glasgow. JM contributed to study conception and design, stage 1 and co-led stage 2 in Bristol. KO contributed to stages 1 and 2. SR contributed to study conception and design, and stage 1. ZR contributed to Stages 1 and 2. CJ was the Principal Investigator. She conceived, designed and led the whole study, co-led stage 1, co-led stage 2 in York and drafted the manuscript. The authors have read, revised and approved the final manuscript.

\section{Funding}

This project was funded by the National Institute for Health Research Health Technology Assessment Programme (12/17/05). The views and opinions expressed therein are those of the authors and do not necessarily reflect those of the Health Technology Assessment Programme, NIHR, NHS or the Department of Health. The funder was not involved in the design of the study, collection, analysis, and interpretation of data or in writing the manuscript.

\section{Availability of data and materials}

The datasets generated during and/or analysed during the current study are not available due to concerns about deductive disclosure.

\section{Ethics approval and consent to participate}

The National Research Ethics Service Committee Yorkshire and The Humber - Leeds East approved the study (13/YH/025). Prior to commencing each workshop the researcher went through the study information sheet and each item on the consent form with the participant. Participants were subsequently asked to mark or initial the item(s) to which they consented.

\section{Consent for publication}

Not applicable.

\section{Competing interests}

$\mathrm{HB}$ sits on the National Institute for Health and Care Excellence (NICE) Committee that is developing guidance on vaccine uptake in the general population. The other authors declare that they have no competing interests. 


\section{Author details}

1Department of Health Sciences, University of York, Heslington, York YO10 5DD, UK. ${ }^{2}$ UCL Great Ormond Street Institute of Child Health, 30 Guilford Street, London WC1N 1EH, UK. ${ }^{3}$ College of Human and Health Sciences, Swansea University, Singleton Park, Swansea SA2 8PP, UK. ${ }^{4}$ School of Health \& Life Sciences, Glasgow Caledonian University, Cowcaddens Road, Glasgow G4 OBA, UK. ${ }^{5}$ University of the West of England, Centre for Child and Adolescent Health, Oakfield House, Oakfield Grove, Bristol BS8 2BN, UK. ${ }^{6}$ Faculty of Health, Social Care and Education, Anglia Ruskin University East Road Campus, Cambridge CB1 1PT, UK.

\section{Received: 12 November 2019 Accepted: 27 September 2020} Published online: 20 October 2020

\section{References}

1. Jenkins L. Preparation study of gypsy/traveller needs. Canterbury: University of Kent; 2010.

2. Aspinall P. Hidden needs identifying key vulnerable groups in data collections: vulnerable migrants, gypsies and travellers, homeless people, and sex workers. Canterbury: University of Kent; 2014

3. Cook B, Wayne G, Valentine A, Lessios A, Yeh E. Revisiting the evidence on health and health care disparities among the Roma: a systematic review 2003-2012. Int J Public Health. 2013;58:885-911.

4. All Ireland Traveller Health Study Team. All Ireland traveller health study our Geels. Dublin: University College Dublin; 2010.

5. Dar O, Gobin M, Hogarth S, Lane C, Ramsay M. Mapping the gypsy traveller community in England: what we know about their health service provision and childhood immunization uptake. J Public Health. 2013;35:404-12.

6. Dixon KC, Mullis R, Blumenfeld T. Vaccine uptake in the Irish Travelling community: an audit of general practice records. J Public Health. 2016;39: e235-41.

7. Department of Health. Measles outbreaks in gypsy and Travellers communitiesGateway Reference Number: 14614. London: Department of Health; 2010.

8. The National Archives. Health protection report; 2012. https://webarchive. nationalarchives.gov.uk/20140714090734/http://www.hpa.org.uk/hpr/ archives/2012/news3412.htm (Accessed 10 Sep 2020).

9. Falagas M, Zarcadoula E. Factors associated with suboptimal compliance to vaccinations in children in developed countries: a systematic review. Curr Med Res Opin. 2008;24:1719-41.

10. Wheelock A, Thomson A, Sevdalis N. Social and psychological factors underlying adult vaccination behavior: lessons from seasonal influenza vaccination in the US and the UK. Expert Rev Vaccines. 2013;12:893-901.

11. Eilers $R$, Krabbe $P$, de Melker $H$. Factors affecting the uptake of vaccination by the elderly in Western society. Prev Med. 2014;69:224-34.

12. Jackson C, Dyson L, Bedford H, Cheater FM, Condon L, Crocker A, et al. UNderstanding uptake of Immunisations in Travelllng aNd gypsy communities (UNITING): a qualitative interview study. Health Technol Assess. 2016;20:72.

13. Jackson C, Bedford $\mathrm{H}$, Cheater FM, Condon L, Emslie C, Ireland L, et al. Needles, jabs and jags: a qualitative exploration of barriers and facilitators to child and adult immunisation uptake among gypsies. Travellers Roma BMC Public Health. 2017;17:254.

14. Mytton J, Bedford H, Condon L, Jackson C. Improving immunisation uptake rates among gypsies, Roma and Travellers: a qualitative study of the views of service providers. J Public Health:fdaa100. https://doi.org/10.1093/ pubmed/fdaa100.

15. Smith D, Newton P. Structural barriers to measles, mumps and rubella (MMR) immunisation uptake in gypsy, Roma and traveller communities in the United Kingdom. Crit Public Health. 2017;27:238-47.

16. Papadopoulos I, Lay M. The health promotion needs and preferences of gypsy travellers in Wales. Diverse Equal Health Care. 2007:4:167-76.

17. Twiselton I, Huntington F. Health needs assessment: Cumbria gypsy travellers. Penrith: NHS Cumbria; 2009.

18. Women and Equalities Committee. Tackling the inequalities faced by gypsy, Roma and Traveller communities; 2019. https://publications.parliament.uk/ pa/cm201719/cmselect/cmwomeq/360/report-summary.html (Accessed 31 Oct 2019).

19. Crocker-Buque T, Edelstein M, Mounier-Jack S. Interventions to reduce inequalities in vaccine uptake in children and adolescents aged $<19$ years: a systematic review. J Epidemiol Community Health. 2017;71:87-97.
20. Kaufman J, Ryan R, Walsh L, Horey D, Leask J, Robinson P, et al. Face to face interventions for informing or educating parents about early childhood vaccination. Cochrane Database Syst Rev. 2018;5:CD010038.

21. Jacobsen Vann JC, Jacobson RM, Coyne-Beasley T, Asafu-Adkei JK, Szilagyi PG. Patient reminder and recall interventions to improve immunization rates (review). Cochrane Database Syst Rev. 2018;1:CD003941.

22. Jarrett C, Wilson R, O'Leary M, Eckersberger LH, the Sage Working Group on Vaccine Hesitancy. Strategies for addressing vaccine hesitancy - a systematic review. Vaccine. 2015;33:4180-90.

23. Medical Research Council. Developing and evaluating complex interventions: new guidance. London: Medical Research Council; 2008

24. Medical Research Council. Process evaluation of complex evaluations. London: Medical Research Council; 2015.

25. Bartholomew LK. Intervention mapping; 2016. http://interventionmapping. com/ Accessed 12 Oct 2019.

26. Michie $S$, Atkins L, West R. The behaviour change wheel. A guide to designing interventions. London: Silverback Publishing; 2014.

27. World Health Organization Regional Office for Europe. Tailoring immunization programmes to reach underserved groups - the TIP approach; 2016. http://www.euro.who.int/en/health-topics/communicablediseases/measles-and-rubella/activities/tailoring-immunization-programmesto-reach-underserved-groups-the-tip-approach [Accessed 31 Oct 2019].

28. Dube E, Leask J, Wolff B, Hickler B, Balaban V, Hosein E, et al. The WHO tailoring immunization Programmes (TIP) approach: review of implementation to date. Vaccine. 2017:36:1509-15.

29. Bovaird T, Stoker G, Jones T, Loeffler E, Pinilla RM. Activating collective coproduction of public services: influencing citizens to participate in complex governance mechanisms in the UK. Int Rev Admin Sci. 2015;82:47-68.

30. Wemyss R, Matthews Z, Jones $H$. The National Gypsy and traveller health inclusion project 2012-2015. Leeds GATE and Friends Families and Travellers: Brighton; 2015.

31. Collins K. Participation in behaviour change: technique or tyranny? In: Spotswood F, editor. Beyond behaviour change. Bristol: Policy Press; 2016. p. 199-216.

32. Van Cleemput P, Bissell P, Harris J. Pacesetters Programme - gypsy, Roma and traveller core strand. Sheffield: University of Sheffield; 2010.

33. Carr S, Lhussier M, Forster N, Goodall D, Geddes L, Pennington M, et al. Outreach programmes for health improvement of traveller communities: a synthesis of the evidence. Public Health Research. 2014;2:3.

34. Riches E, Hamilton S, Reid G. Interventions to improve engagement with immunisation programmes in selected underserved populations. NHS Health Scotland: Edinburgh; 2019.

35. McLeroy K, Bibeau D, Steckler A, Glanz K. An ecological perspective on health promotion programmes. Health Educ Q. 1988;15:351-77.

36. Jackson C, Bedford H, Condon L, Crocker A, Emslie C, Dyson L, et al. UNderstanding uptake of Immunisations in Travelllng aNd gypsy communities (UNITING): protocol for an exploratory, qualitative study. BMJ Open. 2015;5:e008564.

37. Condon L, Bedford H, Ireland L, Kerr SM, Mytton J, Richardson Z, et al. Engaging gypsy, Roma and traveller communities in research: Maximising opportunities and overcoming challenges. Qual Health Res. 2019;29:1324-33.

38. Renfrew M, Dyson L, Herbert G, McFadden A, McCormick F, Thomas J, et al. Developing evidence-based recommendations in public health-incorporating the views of practitioners, service users and user representatives. Health Expect. 2008;11:3-15.

39. Rechel B, Blackburn C, Spencer N, Rechel B. Access to health care for Roma children in central and Eastern Europe: findings from a qualitative study in Bulgaria. Int J Equity Health. 2009;8:24.

40. Office for National Statistics. What does the 2011 census tell us about the characteristics of gypsy or Irish travellers in England and Wales? London: Office for National Statistics; 2014.

41. Brown P, Scullion L, Martin P. Migrant Roma in the United Kingdom. Population size and experiences of local authorities and partners. Final report. Manchester: University of Salford; 2013.

42. The Scottish Parliament. Equal opportunities committee 1st report, 2012 (session 4) where gypsy/Travellers live. Edinburgh: The Scottish Parliament; 2012.

43. The Social Marketing Gateway. Mapping the Roma Community in Scotland. Final report. The Social Marketing Gateway: Glasgow; 2013.

44. Freudenberg N, Franzosa E, Chisholm J, Libman K. New approaches for moving upstream: how state and local health departments can transform practice to reduce health inequalities. Health Educ Behav. 2015;42:46S-56S. 
45. HM Government. Equality act 2010; 2010. http://www.legislation.gov.uk/ ukpga/2010/15/contents Accessed 12 Oct 2019.

46. Francis G. Developing the cultural completence of health professionals working with gypsy travellers report for Mary Seacole development award. London: Department of Health; 2010.

47. Butler M, McCreedy E, Schwer N, Burgess D, Call K, Przedworski J, et al. Improving cultural competence to reduce health disparities. Agency for Healthcare Research and Quality: Rockville; 2016.

48. World Health Organization. Global vaccine action plan 2011-2020; 2011. http://www.who.int/immunization/global_vaccine_action_plan/GVAP_doc_2 011_2020/en/ Accessed 12 Oct 2019.

49. NHS England. Monitoring equalities and health inequalities: a position paper. London: NHS England; 2015.

50. Department of Health. Public health functions to be exercised by NHS England. Service specification no.28 child health information systems (CHIS); 2013. https:/www.gov.uk/government/uploads/system/uploads/ attachment_data/file/192979/28_CHIS_service_specification_VARIATION_13 0422.pdf Accessed 12 Oct 2017.

51. Cromarty H. House of commons library, briefing paper 08083 gypsies and Travellers; 2019. (9 May 2019), https://researchbriefings.parliament.uk/ ResearchBriefing/Summary/CBP-8083\#fullreport. Accessed 7 Nov 2019.

52. McFadden A, Siebelt L, Jackson C, Jones H, Innes N, MacGillivray S, et al. Enhancing gypsy, Roma and Traveller peoples' trust: using maternity and early years' health services and dental health services as exemplars of mainstream service provision. Dundee: University of Dundee; 2018. https:/ doi.org/10.20933/100001117. Accessed 7 Nov 2019

53. National Institute for Health and Care Excellence. Reducing differences in the uptake of immunisations (including targeted vaccines) among children and young peeople aged under 19 years. London: NICE; 2017.

54. Gill P, Macleod U, Lester H, Hegenbarth A. Improving access to healthcare for gypsies and travellers, homeless people and sex workers. London: Royal College of General Practitioners; 2013.

55. Thomas RE, Lorenzetti DL. Interventions to increase inflenza vaccination rates of those 60 years and older. Cochrane Database Syst Rev. 2018, Issue 5. Art. No.: CD005188. https://doi.org/10.1002/14651858.CD005188.pub4.

56. Parry G, Van Cleemput P, Peters J, Walters S, Thomas K, Cooper C. Health status of gypsies and travellers in England. J Epidemiol Community Health. 2007;61:198-204

\section{Publisher's Note}

Springer Nature remains neutral with regard to jurisdictional claims in published maps and institutional affiliations.

Ready to submit your research? Choose BMC and benefit from:

- fast, convenient online submission

- thorough peer review by experienced researchers in your field

- rapid publication on acceptance

- support for research data, including large and complex data types

- gold Open Access which fosters wider collaboration and increased citations

- maximum visibility for your research: over $100 \mathrm{M}$ website views per year

At $\mathrm{BMC}$, research is always in progress.

Learn more biomedcentral.com/submissions 